\title{
Pharmacokinetics and Electrophysiological Effects of Verapamil in Patients with Paroxysmal Supraventricular Tachycardia
}

\author{
Yuichi KOIKE ${ }^{* 1}$ Masayuki SAKURAI*2 Noriyoshi KATO*2 Miri FUJITA*2 \\ Tetsuo NISHINO*2 Kosuke FUJITA*2 Hideya SAITO*1 and Hisakazu YASUDA*2 \\ (Received on May 17, 1983) \\ *1 First Department of Pharmacology and *2 Department of Cardi- \\ ovascular Medicine, Hokkaido University, School of Medicine, \\ Sapporo, Hokkaido
}

Ten mg of verapamil was administered intravenously to eight patients with paroxysmal supraventricular tachycardia. After drug administration, investigation of the pharmacokinetics of verapamil was carried out, and the relationship between plasma verapamil concentration and its electrophysiological effects was studied. After verapamil administration, pharmacokinetic parameters were calculated using a two-compartment open model. Biological half-life ranged from 2.91 to 4.55 hours and apparent volume of distribution ranged from 1.28 to $3.18 \mathrm{~L} / \mathrm{kg}$. Total body clearance ranged from 216 to $733 \mathrm{ml} / \mathrm{min}$.

Verapamil significantly prolonged the AH interval but did not prolong the HV interval. The effective and the functional refractory period of the AV node (ERPAVN and FRPAVN) were also prolonged after verapamil administration. The antegrade echo zone and the supraventricular tachycardia zone were also narrowed in most patients. A concentration-dependent relationship between plasma verapamil and percent increase of both ERPAVN and $\mathrm{AH}$ interval was observed.

Key words : verapamil, paroxysmal supraventricular tachycardia, pharmacokinetic parameter, electrophysiological effect

*1 北海道大学医学部第一薬理学教室 厂 060 札幌市北区北 15 条西 7 丁目

*2 同循環器内科学教室
Verapamil was originally introduced as a coronary vasodilator ${ }^{1)}$. Its antiarrhythmic effect on various experimentally induced arrhythmias was explored during the 1960 ' $\mathrm{s}^{2334)}$. It has also been 
demonstrated that verapamil's antiarrhythmic mechanism differs from those of other antiarrhy. thmic drugs ${ }^{5 / 6)}$. Due to its inhibition of AV nodal conduction, verapamil is effective clinically in atrial flutter, atrial fibrillation and paroxysmal supraventricular tachycardia (PSVT) ${ }^{7889910)}$. Although there are numerous reports on the antiarrhythmic effects of verapamil, relatively few reports have been published on the pharmacokinetic effects of this drug ${ }^{1 / 12(13) 14 / 15}$. However, to understand the antiarrhythmic mechanism of verapamil both its pharmacokinetics and pharmacodynamics must be studied simultaneously. Correlation between plasma verapamil levels and electrophysiological and hemodynamic effects have been demonstrated in animal studies ${ }^{16(17) 18}$. However, there is little comparable clinical data available ${ }^{19}$. Therefore, we have attempted to clarify the relationship between pharmacokinetics of verapamil and its electrophysiological effects in patients with PSVT.

\section{Materials and Methods}

Patients: Eight patients, four males and four females, with a history of recurrent supraventricular tachycardia participated in this study. Ages ranged from 45 to 67 years (mean 57.1) and body weights ranged from 46 to $67.5 \mathrm{~kg}$ (mean 53.4). Normal liver and kidney function were verified by laboratory function tests. None had electrocardiographic evidence of the Wolff-Parkinson-White syndrome. Details of patient characteristics are shown in Tab. 1.

Methods: All drugs were withdrawn 48 hours prior to study. Patients were informed, and written consents were obtained. The electrophysiological studies were performed in postabsorptive and non-sedative state.

Four tri- or quadripolar electrode catheters were inserted, and positioned as follows : high in the right atrium; in the coronary sinus (or pulmonary artery); in the right ventricle to record and stimulate; and the fourth catheter was positioned across the tricuspid valve to record

Tab. 1 Patient Characteristics

\begin{tabular}{cccccccc}
\hline Patient & $\begin{array}{c}\text { Age } \\
(\mathrm{y})\end{array}$ & Sex & $\begin{array}{c}\text { Body weight } \\
(\mathrm{kg})\end{array}$ & $\begin{array}{c}\text { SGOT } \\
(\mathrm{K} . \mathrm{U} .)^{1}\end{array}$ & $\begin{array}{c}\text { SGPT } \\
(\mathrm{K} . \mathrm{U} .)^{1}\end{array}$ & $\begin{array}{c}\text { Serum creatinine } \\
(\mathrm{mg} / \mathrm{d} 1)\end{array}$ & $\begin{array}{c}\mathrm{Ccr}^{2} \\
(\mathrm{~m} \mathrm{~m} / \mathrm{min})\end{array}$ \\
\hline 1 & 45 & $\mathrm{M}$ & 58 & 11 & 7 & 1.2 & 76.0 \\
2 & 49 & $\mathrm{~F}$ & 52 & 15 & 7 & 0.7 & 91.4 \\
3 & 63 & $\mathrm{M}$ & 67.5 & 20 & 29 & 0.8 & 81.0 \\
4 & 67 & $\mathrm{~F}$ & 47 & 22 & 21 & 0.9 & 74.2 \\
5 & 48 & M & 58 & 28 & 29 & 1.1 & -- \\
6 & 56 & M & 52 & 29 & 30 & 0.8 & 107.3 \\
7 & 65 & $\mathrm{~F}$ & 46.5 & 10 & 7 & 0.7 & 92.5 \\
8 & 64 & $\mathrm{~F}$ & 46 & 12 & 8 & 0.6 & 98.3 \\
\hline Mean & 57.1 & & 53.4 & 18 & 17 & 0.9 & 88.7 \\
SD & 8.8 & & 7.4 & 7.5 & 11.0 & 0.2 & 12.2 \\
\hline
\end{tabular}

1: Karmen Unit

2: Creatinine clearance 
His bundle electrogram using the technique described by Sherlag et al. ${ }^{20)}$ Intracardiac electrograms were recorded simultaneously on a multichannel oscilloscopic photographic recorder (Hewlett-Packard 4568) with standard electrocardiographic leads at a paper speed of 50 or $100 \mathrm{~mm} / \mathrm{sec}$. The effective and the functional refractory period of the AV node (ERPAVN and FRPAVN) and the effective refractory period of the right atrium, as described by Wit et al. ${ }^{21}$, were determined using the right atrial extrastimulus technique. The antegrade echo zone (EZ), which is the zone of coupling interval resulting in atrial echoes, and the EZ in which more than one atrial echo could conduct to the ventricle (SVTZ) were also measured using the technique above-mentioned. Thereafter, the ventriculoatrial (V-A) conduction time, the refractory period of the $\mathrm{V}-\mathrm{A}$ conduction both over the concealed accessory pathway and the normal conduction system, and the effective refractory period of the right ventricle were determined by the right ventricular extrastimulus technique.

After the control measurement, $10 \mathrm{mg}$ verapamil was administered intravenously and the same stimulation program was repeated $15 \mathrm{~min}$ after injection. Verapamil injection was completed within a two minute time period. The $\mathrm{AH}$ interval $(\mathrm{AH})$, the $\mathrm{HV}$ interval ( $\mathrm{HV})$, ERPAVN, FRPAVN, the effective refractory period of the atrium, EZ, SVTZ, the V-A conduction time, the refractory period of the $\mathrm{V}-\mathrm{A}$ conduction over the right ventricle were determined at 15, 30, 60, 90 and 120 min thereafter.

Control blood sample was drawn prior to drug administration. Blood was taken 5, 15, 30, 60, 90 and $120 \mathrm{~min}$ during the electrophysiological studies and $3,4,6$ and $8 \mathrm{hr}$ after intravenous injection of verapamil. Blood samples were centrifuged and separated plasma was stored at $-20^{\circ} \mathrm{C}$ prior to analysis.

Verapamil analysis: Plasma verapamil was measured by the fluorometric method described by McAllister and Howell ${ }^{22}$.

Pharmacokinetic analysis: Plasma verapamil concentration after intravenous injection was analyzed using a two-comparment open model. The plasma concentration vs time curve was obtained by least square fitting :

$$
\mathrm{Cp}(\mathrm{t})=\mathrm{Ae}^{-\alpha_{\mathrm{t}}}+\mathrm{Be}^{-\beta_{\mathrm{t}}}
$$

where $C p(t)$ is the plasma concentration at time $t$ after intravenous injection, $\mathrm{A}$ and $\mathrm{B}$ are the zero time intercepts, and $\alpha$ and $\beta$ are the slopes of the distribution and elimination with apparent half-lives $t_{1 / 2} \alpha$ and $t_{1 / 2} \beta$, respectively. The apparent volume of distribution $\left(\mathrm{Vd}_{\text {area }}\right)$ of the drug was calculated with the use of the following formula :

$$
\mathrm{Vd}_{\text {area }}=\frac{\mathrm{I} . \mathrm{V} \text {. dose }}{\beta \times \mathrm{AUC}}
$$

where AUC is the area under plasma concentration vs time curve calculated by means of the trapezoidal rule and extrapolated to infinity. Total body clearance $\left(\mathrm{Cl}_{\mathrm{b}}\right)$ was calculated as follows :

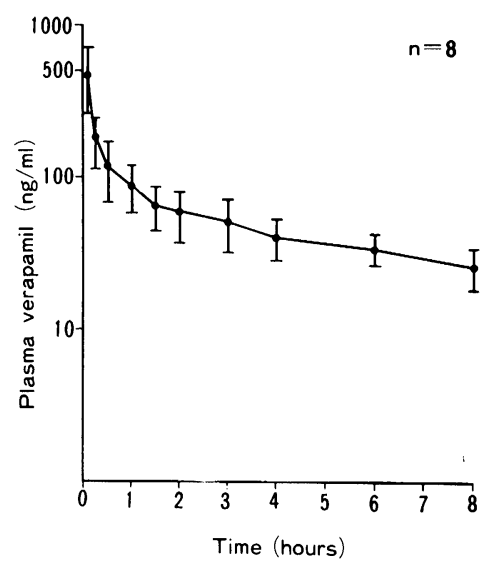

Fig. 1 Mean plasma verapamil concentration after intravenous injection of 10 $\mathrm{mg}$ in 8 patients with paroxysmal supraventricular tachycardia (PSVT). Each value represents as Mean $\pm \mathrm{SD}$. 
Tab. 2 Verapamil Pharmacokinetic Parameters after Intravenous Injection of $10 \mathrm{mg}$ in Patients with Paroxysmal Supraventricular Tachycardia (PSVT)

\begin{tabular}{|c|c|c|c|c|c|c|c|c|c|c|c|c|c|}
\hline Patient & $\begin{array}{c}\alpha \\
\left(h r^{-1}\right)\end{array}$ & $\begin{array}{c}\beta \\
\left(h r^{-1}\right)\end{array}$ & $\begin{array}{r}t_{1 / 2} \alpha \\
(h r)\end{array}$ & $\begin{array}{r}t_{1 / 2} B \\
(h r)\end{array}$ & $\begin{array}{c}\mathrm{K}_{\mathrm{el}} \\
\left(\mathrm{hr}^{-1}\right)\end{array}$ & $\begin{array}{c}\mathrm{K}_{12} \\
\left(\mathrm{hr}^{-1}\right)\end{array}$ & $\begin{array}{c}\mathrm{K}_{21} \\
\left(\mathrm{hr}^{-1}\right)\end{array}$ & $\begin{array}{l}\mathrm{Vd}_{\text {area }} \\
(\mathrm{L} / \mathrm{Kg})\end{array}$ & $\begin{array}{c}\mathrm{V}_{1} \\
(\mathrm{~L} / \mathrm{Kg})\end{array}$ & $\begin{array}{c}\mathrm{V}_{2} \\
(\mathrm{~L} / \mathrm{Kg})\end{array}$ & $\begin{array}{l}\mathrm{Vd}_{\mathrm{ss}} \\
(\mathrm{L} / \mathrm{Kg})\end{array}$ & $\begin{array}{c}\mathrm{Cl}_{\mathrm{b}} \\
(\mathrm{m} 1 / \mathrm{min})\end{array}$ & $\begin{array}{c}\text { AUC } \\
(\mathrm{hr} \cdot \mathrm{ng} / \mathrm{ml})\end{array}$ \\
\hline 1 & 4.81 & 0.18 & 0.14 & 3.85 & 1.04 & 3.12 & 0.83 & 1.94 & 0.33 & 1.25 & 1.58 & 338.23 & 532.82 \\
\hline 2 & 4.09 & 0.20 & 0.17 & 3.48 & 1.04 & 2.47 & 0.78 & 2.62 & 0.47 & 1.49 & 1.96 & 453.05 & 394.73 \\
\hline 3 & 6.43 & 0.18 & 0.11 & 3.80 & 1.21 & 4.42 & 0.97 & 1.83 & 0.22 & 0.99 & 1.21 & 339.00 & 591.44 \\
\hline 4 & 5.30 & 0.16 & 0.13 & 4.38 & 1.22 & 3.55 & 0.69 & 2.31 & 0.30 & 1.54 & 1.84 & 286.14 & 606.38 \\
\hline 5 & 5.90 & 0.24 & 0.12 & 2.91 & 1.40 & 3.73 & 1.01 & 3.18 & 0.54 & 2.01 & 2.55 & 733.51 & 244.50 \\
\hline 6 & 2.63 & 0.21 & 0.26 & 3.30 & 0.69 & 1.35 & 0.80 & 1.28 & 0.39 & 0.66 & 1.05 & 233.37 & 717.09 \\
\hline 7 & 5.79 & 0.17 & 0.12 & 4.11 & 0.59 & 3.71 & 1.67 & 1.73 & 0.50 & 1.11 & 1.61 & 226.95 & 746.28 \\
\hline 8 & 5.80 & 0.15 & 0.12 & 4.55 & 1.29 & 3.98 & 0.69 & 1.86 & 0.22 & 1.28 & 1.50 & 216.79 & 804.67 \\
\hline Mean & 5.09 & 0.19 & 0.15 & 3.80 & 1.06 & 3.29 & 0.93 & 2.09 & 0.37 & 1.29 & 1.66 & 353.38 & 579.74 \\
\hline SD & 1.23 & 0.03 & 0.05 & 0.55 & 0.29 & 0.98 & 0.32 & 0.59 & 0.12 & 0.40 & 0.47 & 172.56 & 187.79 \\
\hline
\end{tabular}

Glossary of symbols

$\begin{array}{ll}A & \text { zero time intercept of 'alpha' or 'distribution' phase } \\ B & \text { zero time intercept of 'beta' or 'elimination' phase } \\ \alpha & \text { exponent for 'alpha' or 'distribution' phase } \\ \mathrm{t}_{1 / 2} \alpha & \text { biological half-life of 'alpha' or 'distribution' phase } \\ \mathrm{t}_{1 / 2} B & \text { biological half-life of 'beta' or 'elimination' phase } \\ \mathrm{K}_{\mathrm{el}} & \text { elimination rate constant } \\ \mathrm{K}_{12} & \text { transfer rate constant from central to peripheral compartment } \\ \mathrm{K}_{21} & \text { transfer rate constant from peripheral to central compartment } \\ \mathrm{Vd}_{\mathrm{area}} & \text { apparent volume of distribution } \\ \mathrm{V}_{1} & \text { volume of central compartment } \\ \mathrm{V}_{2} & \text { volume of peripheral compartment } \\ \mathrm{Vd}_{\mathrm{SS}} & \text { volume of distribution at steady-state } \\ \mathrm{Cl} & \text { total body clearance } \\ \mathrm{AUC} & \text { area under plasma concentration vs time curve }\end{array}$

$$
\mathrm{Cl}_{\mathrm{b}}=\beta \times \mathrm{Vd}_{\text {area }}
$$

The transfer $\left(\mathrm{K}_{12}, \mathrm{~K}_{21}\right)$ and elimination ( $\left.\mathrm{Kel}\right)$ rate constant were calculated by using the values of the $\operatorname{slopes}(\alpha, \beta)$ and intercepts $(A, B)^{2324)}$. Statistical analysis : Pretreatment control period mean and post verapamil administration mean of electrophysiological data were compared using the paired, two-tailed Student's t-test. A p value of less than 0.05 was regarded as the minimum level of statistical significance. Individual concentration-effect relationship data was analyzed by using linear regression by the least square method. Data is expressed as Mean $\pm \mathrm{SD}$.

\section{Results}

Pharmacokinetics : The semilogarithmic plots of drug plasma level vs time for 8 patients are shown in Fig. 1. After intravenous injection, plasma 

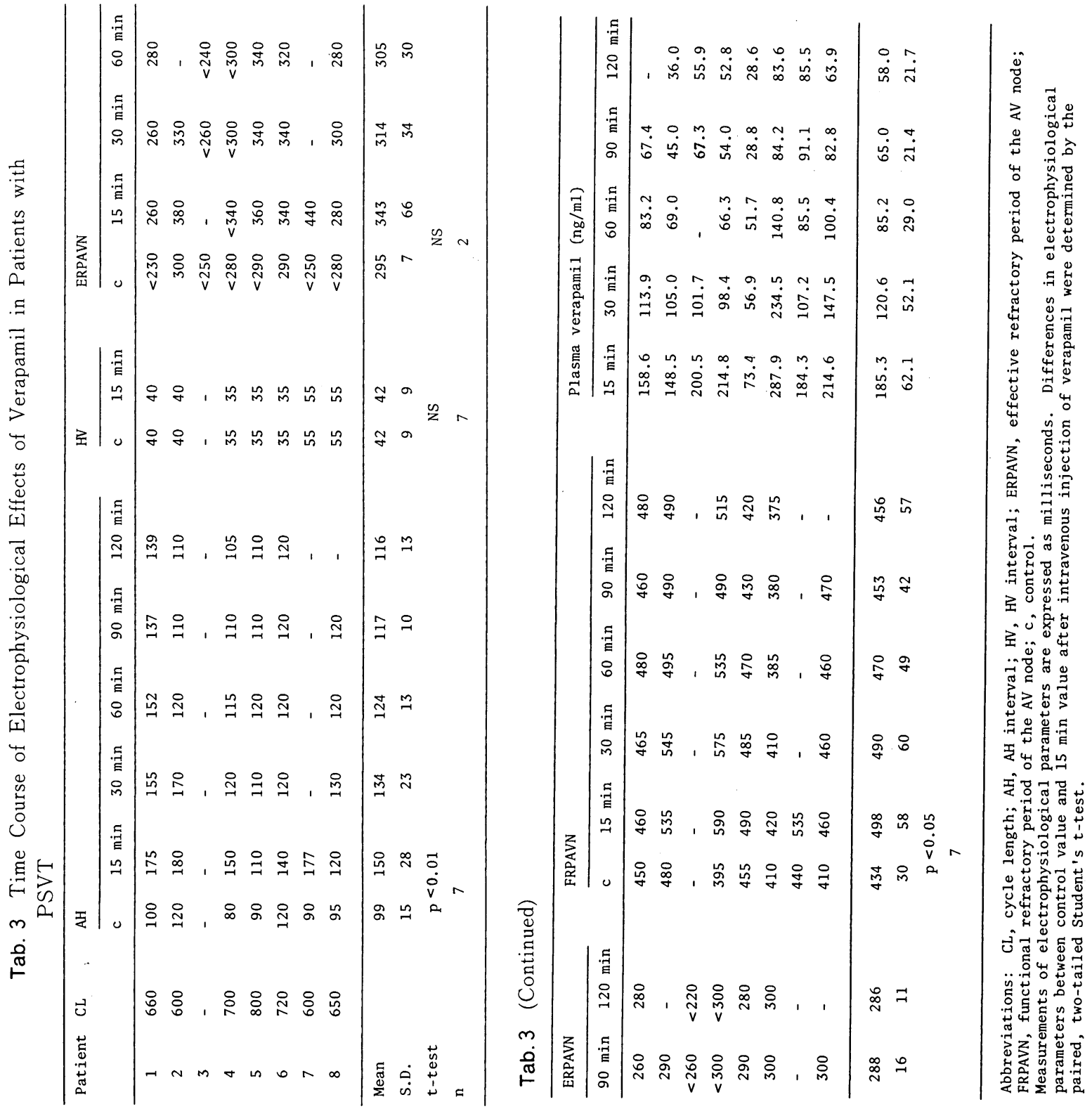


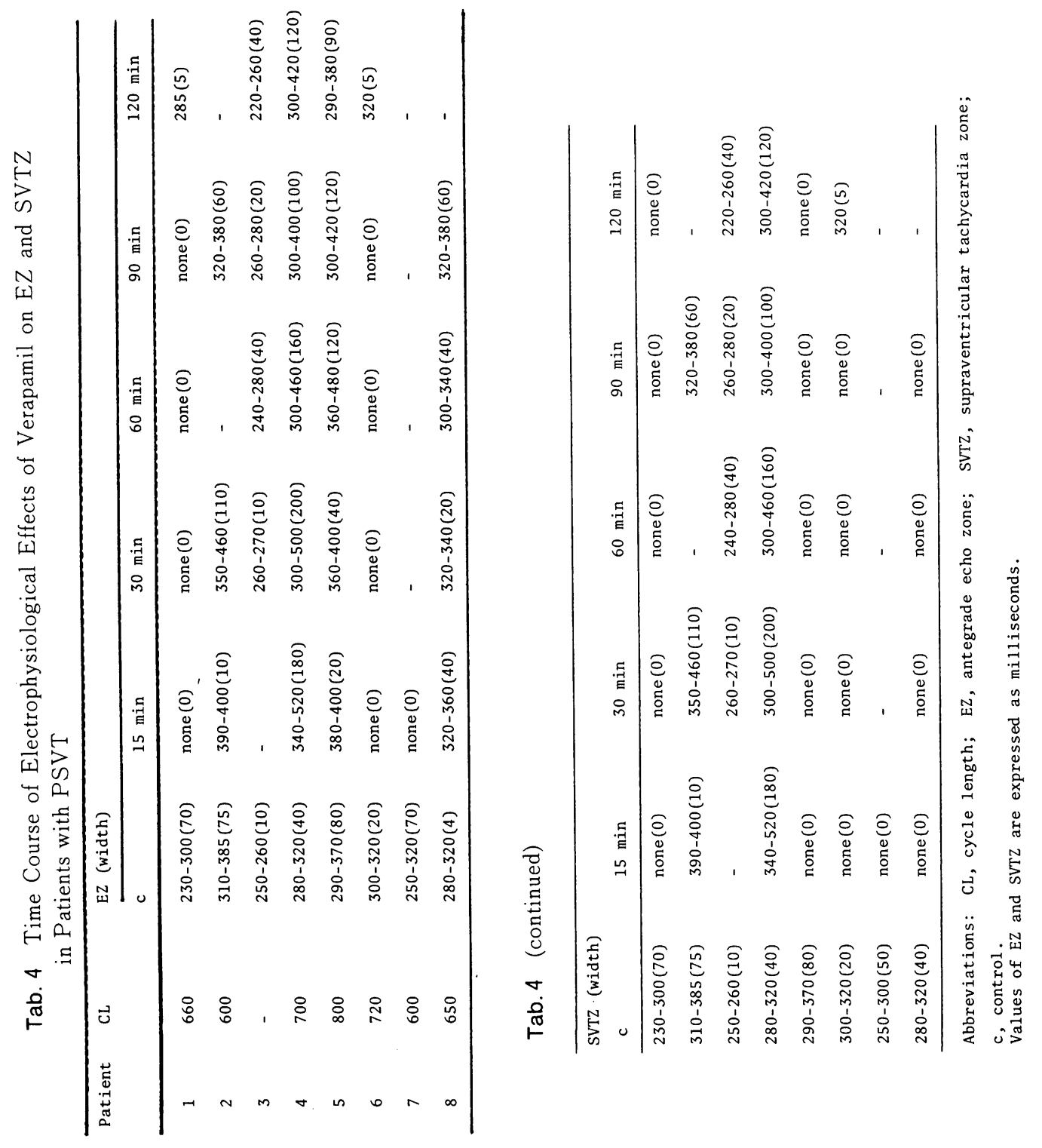




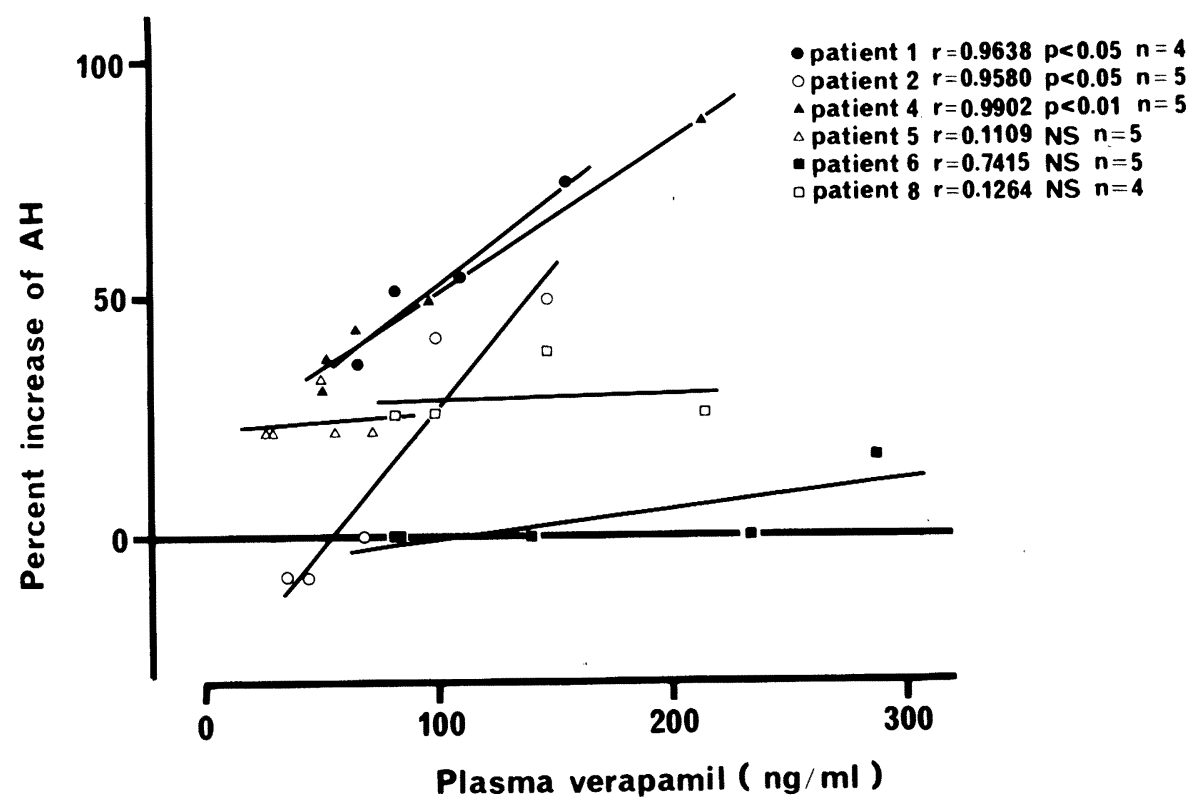

Fig. 2 Relationships between the percent increase of $\mathrm{AH}$ and plasma verapamil concentration.

verapamil levels declined biexponentially. Data was analyzed in accordance with a two-compartment open model.

Relevant pharmacokinetic parameters are listed in Tab.2. The apparent half-life of initial distribution phase $\left(t_{1 / 2} \alpha\right)$ ranged from 0.11 to 0.26 hours. The apparent half-life of elimination phase $\left(t_{1 / 2} \beta\right)$ ranged from 2.91 to 4.55 hours. The apparent volume of distribution ( $\mathrm{Vd}_{\text {area }}$ ) ranged from 1.28 to $3.18 \mathrm{~L} / \mathrm{kg}$, and total body clearance ranged from 216 to $733 \mathrm{ml} / \mathrm{min}$. AUC of verapamil ranged from 394.73 to 804.67 $\mathrm{hr} \cdot \mathrm{ng} / \mathrm{ml}$.

Electrophysiological effects: Maximal effect was obtained 15 minutes after intravenous injection of verapamil. Thereafter, it decreased gradually. The time course of electrophysiological effects is shown in Tab. 3 and 4 . AH was significantly prolonged from $99 \pm 6$ to $150 \pm 11$ msec in His bundle electrocardiogram 15 minutes after injection $(\mathrm{p}<0.01, \mathrm{n}=7)$ (Tab. 3). Mini- mal concentration of verapamil required to prolong $\mathrm{AH}$ was $29 \mathrm{ng} / \mathrm{ml}$. On the other hand, HV was not changed by verapamil. Verapamil also prolonged both ERPAVN and FRPAVN from $295 \pm 7$ to $360 \pm 28 \mathrm{msec}$ and from $434 \pm 11$ to $499 \pm$ 22 mesc, respectively $15 \mathrm{~min}$ after injection (not significant for ERPAVN, $\mathrm{n}=2$ and $\mathrm{p}<0.05$ for FRPAVN, $n=7$ ) (Tab. 3). Minimal concentrations which prolonged ERPAVN and FRPAVN were $29 \mathrm{ng} / \mathrm{ml}$ and $36 \mathrm{ng} / \mathrm{ml}$, respectively.

Verapamil did not effect the refractory period of the atrium, the refractory period of the $\mathrm{V}-\mathrm{A}$ conduction system over the accessory pathway or the effective refractory period of the right ventricle. The width of EZ was narrowed in 5 of the 7 patients and width of SVTZ was narrowed in 6 of 7 patients $15 \mathrm{~min}$ after intravenous injection of verapamil (Tab. 4).

Relationship between plasma concentration and electrophysiological effect: There were positive correlations between the percent increase of $\mathrm{AH}$ 


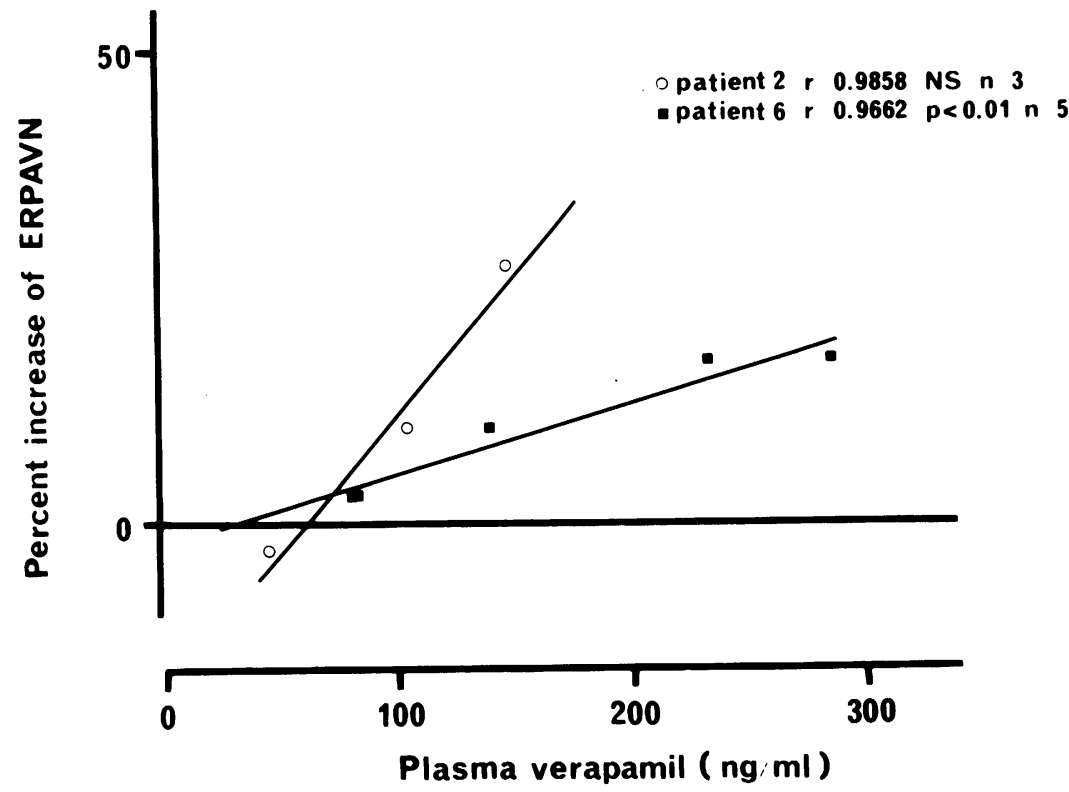

Fig. 3 Relationships between the percent increase of ERPAVN and plasma verapamil concentration.

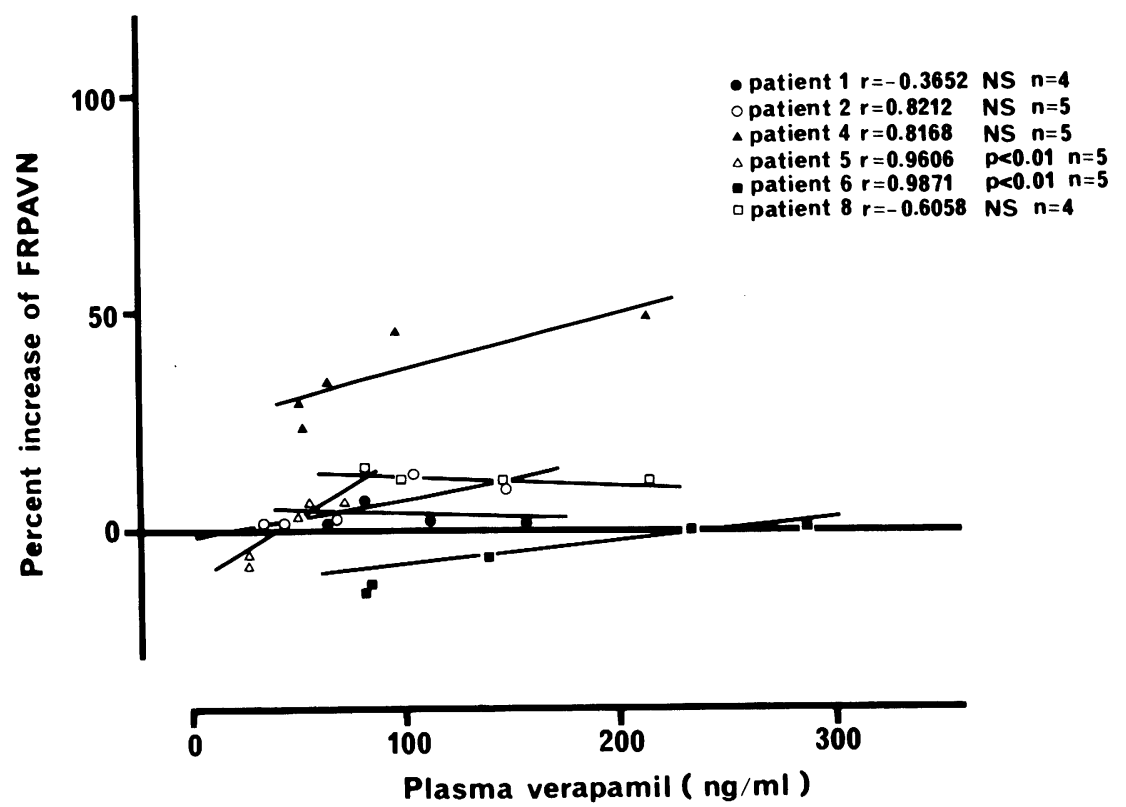

Tab. 4 Relationships between the percent increase of FRPAVN and plasma verapamil concentration.

and plasma verapamil concentration, and verapamil's this correlation was significant in 3 out of 6 patients (Fig. 2). Concerning the verapamil's effect on ERPAVN, although control values were obtained in only two patients, there was a strong positive correlation between the percent increase 
of ERPAVN and plama verapamil concentration, and this correlation was found to be significant in patient 6 (Fig. 3). With regard to the effect on FRPAVN, positive correlations between percent increase of FRPAVN and verapamil concentration were observed in 4 out of 6 patients. Correlation was significant in 2 patients (Fig. 4).

\section{Discussion}

Previously, little had been published concerning disposition kinetics of verapamil in man. The first report that appeared in 1976 demonstrated that plasma verapamil levels showed a biexponential decline and the elimination half-life $\left(t_{1 / 2} \beta\right)$ ranged from 3 to $7 \mathrm{hr}$ in normal subjects ${ }^{11)}$.

The previous study of the pharmacokinetics and relationship between serum concentration and surface electrocardiographic changes demonstrated that the biological half-life of verapamil characteristically ranged between 3 and 4 $\mathrm{hr}$, and that there was a significant correlation between the prolongation of $P Q$ interval and the increase of serum verapamil concentration ${ }^{12}$. These findings concurred with earlier animal experiments ${ }^{16)}$.

The present study was conducted to explore both the pharmacokinetics of intravenous verapamil and the relationship between verapamil concentration and electrophysiological effects in patients with PSVT.

In our present study, there was a two-fold difference in the apparent volume of distribution in patients, but little individual difference between $\mathrm{Vd}_{\text {area }}$ and $\mathrm{Vd}_{\text {ss. }}$. There was a three-fold difference in the total body clearance among them. Most pharmacokinetic parameters approximated those of normal subjects as Koike et al. reported previously ${ }^{12}$. The elimination half-life observed in our study was identical to that observed by Eichelbaum ${ }^{14)}$ and was longer than that reported by Dominic ${ }^{13)}$. Recently, Kates et al. ${ }^{15)}$ reported longer elimination half-life of verapamil. The authors collected blood samples for over $24 \mathrm{hr}$ after intravenous infusion and the data was analyzed using a three-compartment open model. These differences may be attributed to the duration of sampling time. The volume of distribution and plasma clearance were less than those observed in other studies ${ }^{1113141415}$. Discrepancy between our data and others may be due partly to differences in populations.

Verapamil's electrophysiological effect works selectively on the sinus node and the AV node ${ }^{6(25) 26627)}$. More selectively, it has been demonstrated that verapamil depresses the AV node more selectively than the sinus node ${ }^{17}$. The membrane potential of both nodal cells depends upon inward current through the slow channel. Since verapamil interferes with this slow channel, it depresses the intranodal conduction time and prolongs the refractory period of the AV node ${ }^{7226) 28)}$.

Many clinical reports have shown that verapamil prolonged the AV nodal conduction as well as ERPAVN and FRPAVN, but did not prolong the HV interval ${ }^{29)-33)}$. Our results were in agreement with these studies. Furthermore, verapamil narrowed the width of EZ and SVTZ in all of the patients studied. This effect indicates the efficacy of the drug in terminating PSVT. Since most supraventricular tachycardia results from reentry and the AV node is an antegrade limb of the reentry circuit, prolongation of ERPAVN decreases the absolute width of EZ during which atrial premature impulse may induce the reentry and prevents the atrial echo from returning to the ventricle and initiating tachycardia.

In regard to correlation between plasma vera- 
pamil concentration and electrophysiological effects, Mangiardi et al. ${ }^{17)}$ demonstrated in animal experiment that there was a significant correlation between plasma verapamil concentration and $\mathrm{AH}$.interval prolongation. The authors also reported that the functional and the effective refractory period of the AV node increased in a concentration dependent manner.

Our present studies demonstrated that the prolongation of the $\mathrm{AH}$ interval and the increase of ERPAVN were dependent upon plasma verapamil concentration throughout both distribution and elimination phases. Because of the correlation between plasma verapamil concentration and electrophysiological effects, it was speculated that the pharmacodynamic effects of verapamil were dependent upon the concentration (or amount) of the drug in the central compartment. In addition, the minimal effective plasma concentration of verapamil which prolonged the $\mathrm{AH}$ interval and ERPAVN was found to be between 30-40 $\mathrm{ng} / \mathrm{ml}$. But in clinical therapy of arrhythmias, the "minimal effective therapeutic concentration" may be a high level than those mentioned above because critical prolongation of ERPAVN and the effective decrease of width of EZ are required in order to terminate supraventricular tachycardia. In fact, Sung et al. ${ }^{34)}$ reported that plasma verapamil concentrations that successfully terminated supraventricular tachycardia ranged from 72 to $195 \mathrm{ng} / \mathrm{ml}$. In our clinical experience, a concentration range of 50-150 $\mathrm{ng} / \mathrm{ml}$ verapamil has been sufficient to terminate supraventicular tachycardia (unpublished observation).

The present study confirmed our previous observation that verapamil's physiological disposition in patients with PSVT does not differ from that in normal subjects. It also demonstrated that intravenous injection of verapamil prolonged the AV nodal conduction time and increased the effective and the functional refractory period of the AV node. The drug narrowed the width of EZ and SVTZ in most patients. The electrophysiological results indicate that verapamil is effective treatment of PSVT: In addition, the prolongation of the $\mathrm{AH}$ interval and the increase of the refractory period of the AV node were dependent upon plasma verapamil concentration. These facts indicate that rapid injection may possibly produce inappropriate elevation of plasma verapamil concentration, inducing occurrence of adverse effects such as atrioventricular block.

Thus, one should avoid rapid injection of verapamil. Furthermore, it appears that monitoring the concentration of verapamil is a useful way to determine the optimal therapeutic dosage regimen and avoid adverse effects.

Acknowledgements: We thank Eisai Co., Ltd. (Tokyo, Japan) for the gift of verapamil.

\section{References}

1) Hass, H. and Hartfelder, G. : $\alpha$-Isopropyl- $\alpha-$ $\lceil(\mathrm{N}$ methyl-N-homoveratryl- $\gamma$-aminopropyl] - 3, 4-dimethoxyphenylacetonitril, eine Substanz mit coronar-gefässerweiternden Eigenschaften. Arzneim. Forsch., $12: 549-556$ (1962).

2) Schmid, J. R. and Hanna, C. : A comparison of the antiarrhythmic actions of two new synthetic compounds, iproveratril and MJ 1999 with quinidine and propranolol. J. Pharmacol. Exp. Ther., 156:331-338 (1967).

3) Kaumann, A. J. and Aramendia, P. : Prevention of ventricular fibrillation induced by coronary ligation. J. Pharmacol. Exp. Ther., 164:326-332 (1968).

4) Rodrigues-Pereira, E. and Viana, A. P. : The actions of verapamil on experimental arrhythmias. Arzneim. Forsch., 18:175-179 (1968).

5) Singh, B. N. and Vaughan Williams, E. M. : A fourth class of antiarrhythmic action? Effect of verapamil on ouabain toxicity, on atrial and ventricular intracellular potentials, and on other features of cardiac function. Cardiovasc. 
Res., 6 :'109-119 (1972)

6) Cranefield, P. F., Aronson, R. S. and Wit, A. L. : Effect of verapamil on the normal action potential and on a calcium-dependent slow response of canine cardiac Purkinje fibers. Circ. Res., 34 : 204-213 (1974).

7) Schamroth, L. : Immediate effects of intravenous verapamil on atrial fibrillation. Cardiovasc. Res., 5:419-424 (1971).

8) Schamroth, L., Krikler, D. M. and Garrett, C. : Immediate effects of intravenous verapamil in cardiac arrhythmias. Br. Med. J., 1:660-664 (1972).

9) Gotsman, M., Lewis, B., Bakst, A. at al. : Verapamil in life threatening tachyarrhythmias. South Afr. Med. J., 46:2017-2019 (1972).

10) Heng, M. K., Singh, B. N., Roche, A. H. G. et al. : Effects of intravenous verapamil on cardiac arrhythmias. Amer. Heart J., $90: 487-498$ (1975).

11) Schomerus, M., Spiegelhalder, B., Stieren, B. et al. : Physiological disposition of verapamil in man. Cardiovasc. Res., 10:605-612 (1976).

12) Koike, Y., Shimamura, K., Shudo, I. et al. : Pharmacokinetics of verapamil in man. Res. Commun. Chem. Pathol. Pharmacol., 24 : 37-47 (1979).

13) Dominic, J. A., Bourne, D. W. A., Tan, T. G. et al. : The pharmacology of verapamil. III. pharmacokinetics in normal subjects after intravenous drug administration. J. Cardiovasc. Pharmacol., 3 : 25-38 (1981).

14) Eichelbaum, M., Somogyi, A., von Unruh, G. E. et al. : Simultaneous determination of the intravenous and oral pharmacokinetic parameters of d, 1-verapamil using stable isotopelabelled verapamil. Eur. J. Clin. Pharmacol., 19 : 133-137 (1981).

15) Kates, R. E., Keefe, D. L. D., Schwartz, J. et al. : Verapamil disposition kinetics in chronic atrial fibrillation. Clin. Pharmacol. Ther., 30 : 44-51 (1981).

16) McAIIister, R. G. Jr., Bourne, D. W. A. and Dittert, L. W. : The pharmacology of verapamil. I. Elimination kinetics in dogs and correlation of plasma levels with effect on the electrocardiogram. J. Pharmacol. Exp. Ther., 202 : 38-44 (1977).

17) Mangiardi, L. M., Hariman, R. J., McAllister,
R. G. Jr. et al. : Electrophysiologic and hemodynamic effects of verapamil. Correlation with plasma drug concentrations. Circulation, 57 : 367-372 (1978).

18) Danilo, P. Jr., Hordof, A. J., Reder, R. F. et al. : Effects of verapamil on electrophysiologic properties of blood superfused cardiac Purkinje fibers. J. Pharmacol. Exp. Ther., 213: 222-227 (1979).

19) Dominic, J., McAllister, R. G. Jr., Kuo, Chien-S. et al. : Verapamil plasma levels and ventricular rate response in patients with atrial fibrillation and flutter. Clin. Pharmacol. Ther., 26: 710-714 (1979).

20) Scherlag, B. J., Lau, S. H., Helfant, R. M. et al. : Catheter technique for recording His bundle activity in man. Circulation, 39 : 13-18 (1969).

21) Wit, A. L., Weiss, M. B., Berkowitz, W. D. et al. : Patterns of atrioventricular conduction in the human heart. Circ. Res., $27: 345-359$ (1970).

22) McAllister, R. G. and Howell, S. M. : Fluorometric assay of verapamil in biological fluids and tissues. J. Pharmacol. Sci., $65: 431-432$ (1976).

23) Gibaldi, M. and Perrier, D. : Two-compartment model. Bibaldi and Perrier (Ed.) : Drug and the pharmaceutical sciences Vol. 1, Pharmacokinetics. Marcel Dekker, N. Y., pp. 48-69 (1975).

24) Greenblatt, D. J. and Koch-Weser, J. : Clinical pharmacokinetics (First of Two Parts).N. Engl. J. Med., $293:$ 702-705 (1975).

25) Ross, G. and Jorgenssen, C. R. : Cardiovascular action of iproveratril. J. Pharmacol. Exp. Ther., 158: 504-509 (1967).

26) Zips, D. P. and Fischer, J. C. : Effects of agents which inhibit the slow channel on sinus node automaticity and atrioventicular conduction in the dog. Circ. Res., $34: 184-192$ (1974).

27) Singh,B. N. and Roche, A. H. G. : Effects of intravenous verapamil on hemodynamics in patients with heart disease. Am. Heart J., 94 : 593-599 (1977).

28) Zipes, D. P. and Mendez, C. : Action of manganese ions and tetrodotoxin on atrioventricular nodal transmembrane potentials in isolated rabbit hearts. Circ. Res., 32:447-454 (1973). 
29) Husaini, M. H., Kvasnicka, J., Ryden, L. et al. : Action of verapamil on sinus node, atrioventricular, and intraventricular conduction. Brit. Heart J., 35 : 734-737 (1973).

30) Roy, P. R., Spurrell, R. A. J. and Sawton, G. E. : The effect of verapamil on the conduction system in man. Postgrad. Med. J., $50: 270-275$ (1974).

31) Rizzon, P., Biase, M. D., Calabrese, P. et al. : Electrophysiologic evaluation of intravenous verapamil in man. Eur. J. Cardiol., $6: 179-194$ (1977).

32) Tonkin, A. M., Aylward, P. E., Joel, S. E. et al.
: Verapamil in prophylaxis of paroxysmal atrioventricular nodal reentrant tachycardia. J. Cardiovasc. Pharmacol., 2:473-486 (1980).

33) Wellens, H. J. J., Tan, S. L., Bar, F. W. H. et al. : Effect of verapamil studied by programmed electrical stimulation of the heart in patients with paroxysmal re-entrant supraventricular tachycardia. Br. Heart J., $39: 1058-1066$ (1977)

34) Sung, R. J., Elser, B. and McAllister, R. G. Jr. : Intravenous verapamil for termination of re-entrant supraventricular tachycardias. Ann. Intern. Med., 93 : 682-689 (1980). 